\title{
Different Regulatory Sequences Control Creatine Kinase-M Gene Expression in Directly Injected Skeletal and Cardiac Muscle
}

\author{
CHRISTOPHER K. VINCENT, ANTONIO GUALBERTO, CHANDRASHEKHAR V. PATEL, \\ AND KENNETH WALSH* \\ Department of Physiology and Biophysics, Case Western Reserve University School of Medicine, \\ 2109 Adelbert Road, Cleveland, Ohio 44106
}

Received 27 August 1992/Returned for modification 13 October 1992/Accepted 18 November 1992

\begin{abstract}
Regulatory sequences of the $\mathrm{M}$ isozyme of the creatine kinase (MCK) gene have been extensively mapped in skeletal muscle, but little is known about the sequences that control cardiac-specific expression. The promoter and enhancer sequences required for MCK gene expression were assayed by the direct injection of plasmid DNA constructs into adult rat cardiac and skeletal muscle. A 700-nucleotide fragment containing the enhancer and promoter of the rabbit MCK gene activated the expression of a downstream reporter gene in both muscle tissues. Deletion of the enhancer significantly decreased expression in skeletal muscle but had no detectable effect on expression in cardiac muscle. Further deletions revealed a CArG sequence motif at position -179 within the promoter that was essential for cardiac-specific expression. The CArG element of the MCK promoter bound to the recombinant serum response factor and YY1, transcription factors which control expression from structurally similar elements in the skeletal actin and c-fos promoters. MCK-CArG-binding activities that were similar or identical to serum response factor and YY1 were also detected in extracts from adult cardiac muscle. These data suggest that the MCK gene is controlled by different regulatory programs in adult cardiac and skeletal muscle.
\end{abstract}

Cardiac and skeletal muscle are functionally similar, highly differentiated tissues that can be distinguished by the expression of distinct tissue-specific isoforms of contractile proteins, receptors, ion channels, and cytosolic enzymes. Numerous DNA regulatory elements, transcription factors, and determination genes required for expression in skeletal muscle have been identified $(17,19,29,30,36,37,40,42$, 45), but far less is known about the developmental molecular biology of cardiac muscle. These studies are complicated by the lack of cardiac cell lines and by the tendency of cultured cells to express the fetal isoforms of muscle-specific genes $(3,8,9)$. Recently, adult cardiac and skeletal muscle tissues have been shown to take up directly injected plasmid DNA and to express reporter genes from viral and muscle-specific regulatory sequences $(1,2,5,21,25,33,43,44)$. Expression from these extrachromosomal, circular plasmids is detected in a small number of myocytes at the site of injection, and expression can persist for months. The simplicity of this technique and the stability of expression has led to the belief that the direct intramuscular injection of DNA may ultimately be used to deliver vaccines, hormones, and other polypeptides to adult organisms, thereby requiring the identification of gene regulatory sequences that control expression in terminally differentiated tissues.

We chose to investigate the $M$ isozyme of the creatine kinase (MCK) gene by the direct injection method because, unlike the case for myosin and actin, the same isoform is expressed in cardiac and skeletal muscle, and because its regulatory sequences have been extensively characterized in skeletal muscle cell culture and in transgenic mice studies $(12,16-20,22,36,37,45)$. Furthermore, the MCK enhancer

\footnotetext{
${ }^{*}$ Corresponding author.
}

contains E-box regulatory elements that are essential for expression in skeletal muscle cell lines. E-box elements are bound by a class of helix-loop-helix transcription factors that can induce myogenesis when they are overexpressed (30, 42). Normally these myogenic determination proteins are expressed only in skeletal muscle, not in cardiac muscle or any other cell type. Thus, it was of interest to determine whether these same sequences were required for MCK expression in cardiac tissue, in which a cardiomyocytespecific helix-loop-helix gene has yet to be identified.

In the study described here, we used the direct gene injection method to compare sequences that regulate rabbit MCK expression in adult rat cardiac and skeletal muscle. Deletion of the enhancer, which contains multiple conserved sequence motifs, had no effect on reporter gene expression in cardiac muscle, but these enhancer sequences were required for expression in directly injected skeletal muscle. Further deletion analyses revealed that a conserved $5^{\prime}$ CCATACAAGG-3' sequence, or CArG motif (29), in the promoter was essential for expression in adult cardiac tissue. The critical role of this MCK promoter CArG element had not been detected in previous cell culture studies. Electrophoretic mobility shift assays were used to test the binding of known CArG element transcription factors to this MCK regulatory sequence $(13,38,40)$. Recombinant serum response factor (SRF) and YY1 specifically bound to the CArG element from the MCK promoter. Furthermore, endogenous DNA-binding activities that were similar or identical to SRF and YY1 could be detected in extracts made from adult cardiac tissue. These data demonstrate that different regulatory sequences control MCK expression in adult cardiac and skeletal muscle and that the E-box elements within the enhancer are not required for MCK expression in adult cardiac tissue. 


\section{MATERIALS AND METHODS}

Plasmid constructions. Construction of the -1200 MCKchlorampenicol acetyltransferase (CAT) plasmid was described previously (45); this construct contains sequences of the rabbit MCK gene from positions -1200 to +54 relative to the start of transcription. For many experiments in this study, MCK fragments were subcloned into plasmid pSVOLUC (7). MCK fragments from -650 to -312 and to -119 were excised from corresponding pLK-CAT vectors (45) with $P v u$ I and HindIII and subcloned into the same sites in pSVO-LUC. MCK fragments -250 and -168 were excised from the corresponding CAT vector by digestion with HindIII and subcloned into the HindIII site of pSVO-LUC. All constructs were confirmed by dideoxy DNA sequence analysis. The additional MCK-luciferase constructs were made by subcloning MCK gene regulatory sequences into the pGL-LUC vector (Promega), which has the firefly luciferase reporter gene downstream from a multiple cloning sequence. For this second series of constructs, the -250 MCK and -168 MCK promoter fragments were excised from the corresponding pSVO-LUC vector and subcloned into the HindIII site of pGL-LUC. The -221 MCK and -190 MCK constructs had promoter fragments that were amplified from the $-650 \mathrm{MCK}$ construct by polymerase chain reaction (PCR) and subcloned into the pGL-LUC vector. PCR primers had the following sequences:

\section{5'-CGCGAGATCTTCCCCCGCCAGCCCGACTCA-3' (-221 MCK) 5'-CGCGAGATCTCCTGGGGCGGCCCATACAAG-3' (-190 MCK) 5'-AGAGGATAGAATGGCGCCGG-3' (luciferase)}

The PCR reaction mixtures contained 2 to $3 \mathrm{pM}-650$ MCK-LUC plasmid as a template and $10 \mu \mathrm{M}$ appropriate primers. The PCR cycle consisted of a 30-s step for denaturation at $94^{\circ} \mathrm{C}$, annealing at $35^{\circ} \mathrm{C}$, and extension at $72^{\circ} \mathrm{C}$. The resulting 275- and 144-bp fragments, with flanking $B g l I I$ and HindIII sites, were digested with the restriction enzymes and subcloned into the corresponding sites of the pGL-LUC vector. The relevant regions of these constructs were sequenced by the dideoxy-chain termination method.

Plasmid pRSV-CAT has the long terminal repeat of the Rous sarcoma virus (RSV) upstream from the CAT gene (10). Plasmid pSV2-CAT contains the simian virus 40 (SV40) promoter and enhancer fused to the CAT gene (11), and the cytomegalovirus (CMV)-luciferase plasmid contains the CMV early promoter fused to the firefly luciferase gene (24). pGL-LUC plasmids containing the SV40 promoter and enhancer or promoter alone were from Promega. All plasmids were prepared with Qiagen columns according to the directions of the manufacturer.

Direct gene injection. Eight-week-old adult male SpragueDawley rats weighing $350 \mathrm{~g}$ were anesthetized by intramuscular injection of ketamine $(150 \mathrm{mg} / \mathrm{kg})$ and xylazine $(3$ $\mathrm{mg} / \mathrm{kg}$ ). For the heart injections, rats were intubated and artificially ventilated with a model 681 (Harvard) rodent respirator $(2,25)$. A left lateral thoracotomy was performed to expose the heart, the pericardium was removed, and 100 to $150 \mu \mathrm{g}$ of plasmid in a 30 - to $50-\mu \mathrm{l}$ solution of $0.1 \mathrm{M} \mathrm{NaCl}$ was injected with a 30-gauge needle into the apex of the left ventricle. Typically injections contained $100 \mu \mathrm{g}$ of test plasmid with the luciferase reporter gene and $50 \mu \mathrm{g}$ of pRSV-CAT as the coinjected control. Skeletal muscle injections were performed by surgically exposing the quadriceps muscle and injecting $100 \mu \mathrm{g}$ of the test plasmid with $50 \mu \mathrm{g}$ of pRSV-CAT plasmid DNA into the rat hind limb. Postoperatively, rats were housed an cared for according to National
Institutes of Health guidelines. Five days after injection, the rats were sacrificed and the injected portions of heart or hind limb skeletal muscle tissues were removed, rinsed with water, and quick-frozen in liquid $\mathrm{N}_{2}$. After being ground in liquid $\mathrm{N}_{2}$ with a mortar and pestle, the tissue was homogenized in $1 \mathrm{ml}$ of ice-cold lysis solution containing $0.1 \mathrm{M}$ Tris $\left(\mathrm{pH} \mathrm{7.5)}\right.$ and $0.01 \mathrm{M} \mathrm{MgCl}{ }_{2}$ with the proteinase inhibitors aprotinin $(2 \mu \mathrm{g} / \mathrm{ml})$, phenylmethylsulfonyl fluoride $(100 \mu \mathrm{g} /$ $\mathrm{ml})$, EDTA $(1 \mathrm{mM})$, leupeptin $(2 \mu \mathrm{g} / \mathrm{ml})$, and pepstatin $(1$ $\mu \mathrm{g} / \mathrm{ml}$ ) (44). Homogenization was performed in a 7-ml glass tissue grinder (Wheaton) by five to six strokes or until the tissue resistance was minimal. The homogenate was then centrifuged at $10,000 \times g$ for $10 \mathrm{~min}$ at $4^{\circ} \mathrm{C}$, and the supernatant was assayed for luciferase and CAT activities.

Luciferase and CAT assays. Extracts from muscle tissues, typically $20 \mu \mathrm{l}$, were assayed for luciferase activity (4). Light production in relative light units (RLU) was measured for 10 $s$ with a model LB9501-Lumat luminometer (Berthold). To account for differences in the tissue mass prior to extract preparation, luciferase activity is calculated as the total RLU, or the RLU that would be produced by the total volume of heart extract. CAT activity in $100 \mu$ l of extract, resulting from the coinjected internal control plasmid (pRSV-CAT), was determined by the method of Gorman et al. (11). Standard conditions for these assays included a $65^{\circ} \mathrm{C}$ preincubation for $10 \mathrm{~min}$ to inactivate endogenous CAT inhibitory activity, followed by a $37^{\circ} \mathrm{C}$ incubation for $16 \mathrm{~h}$ in the presence of $\left[{ }^{14} \mathrm{C}\right]$ chloramphenicol and acetyl coenzyme A. The proportion of acetylated chloramphenicol, or p(CAT conversion), was determined following thin-layer chromatography, and this value was used to adjust the total RLU value to account for differences in the injection efficiency.

DNA-binding factor preparation. Endogenous DNA-binding factors were partially purified from an adult cardiac muscle extract by heparin-Sepharose chromatography. Approximately $10 \mathrm{~g}$ of cardiac muscle from adult male SpragueDawley rats was homogenized by Dounce grinding as described above. Ultrasonic vibration was performed for $2 \mathrm{~min}$ per sample in four 30-s intervals, using $24 \mathrm{ml}$ of buffer that contained $20 \mathrm{mM} N$-2-hydroxyethylpiperazine- $N^{\prime}$-2-ethanesulfonic acid (HEPES; $\mathrm{pH} 8.0$ ), $5 \mathrm{mM} \mathrm{MgCl}_{2}$, and $10 \%$ glycerol. The homogenate was centrifuged at $10,000 \times g$ for $15 \mathrm{~min}$, and the supernatant was applied to a $30-\mathrm{ml}$ heparinSepharose (Pharmacia) column that was equilibrated in the homogenization buffer containing $150 \mathrm{mM} \mathrm{NaCl}$. Proteins were eluted from the column at a linear flow rate of 0.7 $\mathrm{cm} / \mathrm{min}$ with a linear gradient from 150 to $1,000 \mathrm{mM} \mathrm{NaCl}$. A fraction eluting between 350 and $750 \mathrm{mM} \mathrm{NaCl}$ contained SRF and MAPF1 (endogenous YY1 activity). Protein fractions were stored at $-80^{\circ} \mathrm{C}$. Recombinant YY1 was expressed in Escherichia coli as a histidine (H6)-tagged fusion protein that was purified by nickel chelate chromatography (Qiagen) according to the directions of the manufacturer. Recombinant SRF was also expressed in $E$. coli, and DNAbinding assays were performed with lysate that contained approximately $0.5 \%$ SRF. The levels of active, recombinant YY1 and SRF were estimated by measuring the concentration of the nucleoprotein complex at saturating levels of DNA-binding sites.

Electrophoretic mobility shift assays. Complementary oligonucleotides were synthesized with a model 391EP (Applied Biosystems) DNA synthesizer. The MCK-CArG and chicken skeletal actin muscle regulatory elements (MRE) duplex probes were synthesized with SalI-compatible overhangs, and the mouse serum response element (SRE) probe was provided by M. Z. Gilman. The duplex portions of these 


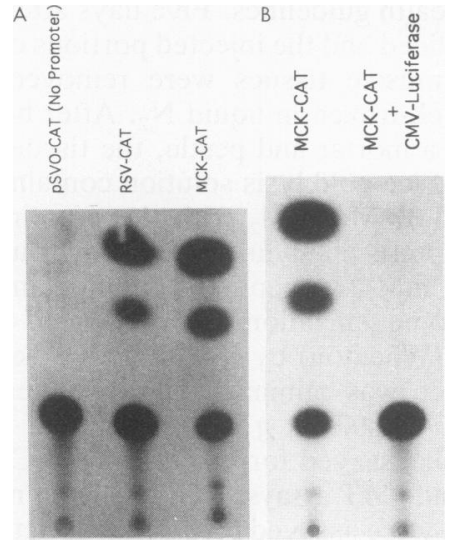

FIG. 1. Promoter-dependent expression and promoter-specific inhibition of directly injected DNA constructs. (A) Expression from the direct cardiac injection of plasmid DNA containing the CAT reporter gene and no regulatory sequences (pSVO-CAT), the RSV long terminal repeat (RSV-CAT), or rabbit MCK regulatory sequences (MCK-CAT). The MCK regulatory fragment was from positions -1200 to +54 relative to the start of transcription. Each injection contained $100 \mu \mathrm{g}$ of test plasmid. (B) Inhibition of MCKCAT expression by coinjection of the CMV-luciferase plasmid construct. Rat hearts were injected with $100 \mu \mathrm{g}$ of MCK-CAT in the presence or absence of $50 \mu \mathrm{g}$ of the CMV-luciferase plasmid. Extract preparations and luciferase and CAT assays were performed as described in Materials and Methods.

sequences are as follows:

$\begin{array}{cc}\text { MCK-CArG } & \text { GGGGCGGCCCATACAAGGGATGGGGC } \\ & \text { CCCCGCCGGGTATGTTCCGTACCCCG } \\ \text { c-fos SRE } & \text { CCTTTACAACAGGATGTCCATATTAGGACATCTGCGTCAGCAG } \\ & \text { GGAAAGCTTGTCCTACAGGTATAATCCTGTACACGCAGTCGTC } \\ \alpha \text {-actin MRE GCCCGACACCCAAATATGGGGACGGCG } \\ \text { CGGGCTGTGGTTTATACCGCTGCCGGC }\end{array}$

Oligonucleotide duplexes were end labeled with polynucleotide kinase and $\left[\gamma^{-32} \mathrm{P}\right] \mathrm{ATP}$ and were purified with Elutip-D columns (Schleicher \& Schuell) according to the directions of the manufacturer. Reaction mixtures contained the indicated amounts of protein fraction, $1 \mathrm{nM}$ radiolabeled probe, $10 \mathrm{mM}$ Tris ( $\mathrm{pH} 7.5$ ), $30 \mathrm{mM} \mathrm{KCl,} 1 \mathrm{mM}$ EDTA, 1 $\mathrm{mM}$ dithiothreitol, $8 \%$ glycerol, and 0.2 to $0.4 \mu \mathrm{g}$ of poly(dI$\mathrm{dC}_{2}$ in a $10-\mu$ l total volume. Following a 90 -min incubation at room temperature, binding mixes were loaded onto a $5 \%$ polyacrylamide gel and electrophoresed at $20 \mathrm{~V} \mathrm{~cm}^{-1}$ in 22 mM Tris-borate buffer with $0.5 \mathrm{mM}$ EDTA. Gels were dried and exposed to film for $8 \mathrm{~h}$ at $-70^{\circ} \mathrm{C}$ with an intensifying screen.

\section{RESULTS}

Promoter-dependent expression and promoter-specific competition in directly injected heart. A plasmid construct, containing the previously mapped promoter and enhancer of the rabbit MCK gene (45), was capable of expressing a downstream CAT reporter gene in directly injected, adult rat cardiac tissue (Fig. 1A). The level of expression from the MCK-CAT construct was comparable to that obtained from pRSV-CAT, which contains the long terminal repeat of RSV (10), but no significant activity was detected in hearts injected with pSVO, which has no regulatory sequences upstream from the CAT reporter gene. These results demonstrated that promoter-dependent expression could be ob-

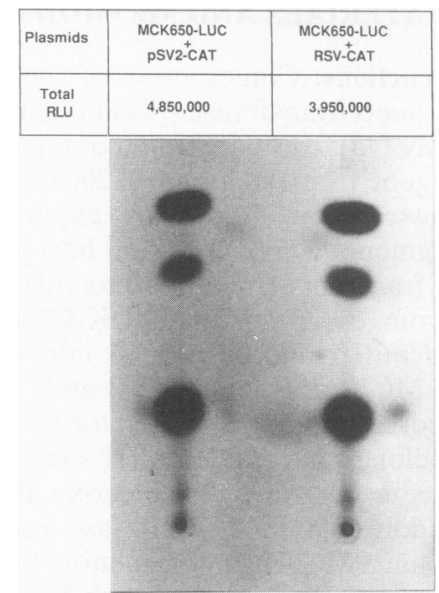

FIG. 2. Evidence that MCK-luciferase expression is not inhibited by coinjection of pSV2-CAT or pRSV-CAT. Adult rat hearts were injected with $100 \mu \mathrm{g}$ of a plasmid containing MCK $5^{\prime}$ flanking sequences (positions -650 to +54 relative to the start of transcription) upstream from the luciferase reporter gene and either $100 \mu \mathrm{g}$ of pSV2-CAT, which contains the SV40 regulatory sequences, or 100 $\mu \mathrm{g}$ of pRSV-CAT. Total RLU represents the luciferase activity of the total extract volume.

tained in adult cardiac tissue by the direct injection of MCK DNA. However, multiple trials revealed that the levels of expression could vary significantly between injections. For example, the extent of CAT conversion produced by extracts made from hearts injected with the same pRSV-CAT preparation were $1.4,24.8,84.0,79.9,17.8,89.6,98.5,29.3$, $11.2,12.4,23.1,22.0,1.8,10.2,3.1,19.9$, and $10.2 \%$. This general lack of reproducibility has been noted by others (44), and it poses a problem for the mapping of regulatory regions within genes. To control for variability between injections, an internal control plasmid, containing the luciferase gene under the control of the CMV long terminal repeat (24), was coinjected. Surprisingly, no significant MCK-CAT activity could be detected in extracts from eight of eight injections, but luciferase activity could be detected, indicating the uptake of foreign DNA (Fig. 1B). Expression from the MCK sequence was detected (six of eight injections) only when the CMV-luciferase plasmid was omitted from the injected solution. These data suggest that CMV sequences compete for limiting transcription factors that are required for MCK expression.

Plasmids containing the SV40 and RSV regulatory sequences were also tested for their ability to inhibit expression from the MCK promoter-enhancer. In this experiment, the MCK 5' flanking sequences were subcloned upstream from the luciferase reporter gene for increased sensitivity, while the viral regulatory sequences were upstream from the CAT reporter gene. Relatively high levels of luciferase activity were produced from the MCK construct in the presence of either viral sequence, and the viral sequences were also capable of significant CAT reporter gene expression (Fig. 2). These data indicate that the MCK construct is compatible with SV40 or RSV sequences in directly injected cardiac tissues. Furthermore, there was a linear relationship between the luciferase activity obtained from the MCK sequences and transfection efficiency, as determined by the CAT activity produced by the RSV sequences (not shown). These data suggest that the rate of transcription is first order with respect to the amount of test plasmid that enters the 
cell. Thus, for all of the cardiac injection experiments described below, the activity of the 5 ' flanking sequences of MCK was evaluated by measuring luciferase activity produced by the downstream reporter gene. Luciferase activity was then adjusted to the level of CAT activity produced by the coinjected pRSV-CAT to account for differences in injection efficiency.

The MCK enhancer is required for expression in directly injected skeletal muscle, but the promoter is sufficient in cardiac muscle. Enhancer and promoter sequences for the MCK genes have been designated by a combination of functional studies in cell culture and by comparisons of conserved sequences upstream from the MCK genes of many species $(12,16-19,22,36,37,45)$. The enhancer has been mapped between positions -650 and -450 in the rabbit gene, and it contains numerous gene regulatory motifs (Fig. 3 ). A conserved region that contains the muscle-specific promoter has been mapped between positions -250 and +54. To test the function of these upstream sequences, serially deleted fragments of the rabbit MCK 5' flanking region were fused to the luciferase reporter gene. All constructs have the same $3^{\prime}$ end at position +54 .

The deletion of the MCK enhancer sequences had no detectable effect on expression in adult cardiac muscle (Fig. 3 ). Instead, the major decrease in activity was produced by the deletion of promoter sequences between positions -250 and -168 . There was no detectable change in this expression pattern when the control plasmid was omitted from the injection solution. To test the expression properties of the enhancer further, the $-650 \mathrm{MCK}$ and the $-250 \mathrm{MCK}$ constructs were injected into the quadriceps muscle of adult rats. In this skeletal muscle tissue, the promoter sequences alone provided a low level of expression, but significantly more expression was detected by the inclusion of the enhancer (Fig. 4A). These data are consistent with previous findings in myogenic cell lines, in which the enhancer activates expression 4 - to 30 -fold $(16,19,36,45)$, but are in marked contrast to the expression pattern in directly injected cardiac muscle, in which promoter sequences alone are sufficient for high levels of expression (Fig. 4B). We note, however, that the overall level of MCK expression is much higher in cardiac muscle than in skeletal muscle (compare Fig. 4A and B). In separate experiments, expression from the CMV-luciferase plasmid was an average of 12-fold greater when the plasmid was injected into cardiac muscle than when it was injected into skeletal muscle (not shown), and higher levels of viral regulatory sequence expression in cardiac relative to skeletal muscle have been reported by others as well $(2,21)$. These data indicate that the higher level of MCK expression in cardiac muscle is due to a higher transfection efficiency in this tissue.

Luciferase gene constructs containing the SV40 promoter and enhancer or the SV40 promoter alone were injected into cardiac muscle to test whether this tissue is capable of responding to enhancer sequences. Inclusion of the SV40 enhancer dramatically increased expression of the luciferase reporter gene. These results demonstrate that adult cardiac tissue is capable of responding to enhancer sequences that are delivered by the direct injection method (Fig. 4C). Thus, the ineffectiveness of the MCK enhancer sequences in adult cardiac muscle is not due to the inability of the direct injection technique to detect enhancer function, but appears to be due to fundamental differences between the transcriptional apparatus of cardiac and skeletal muscle.

A conserved CArG motif in the MCK promoter is essential for expression in directly injected cardiac muscle. Additional

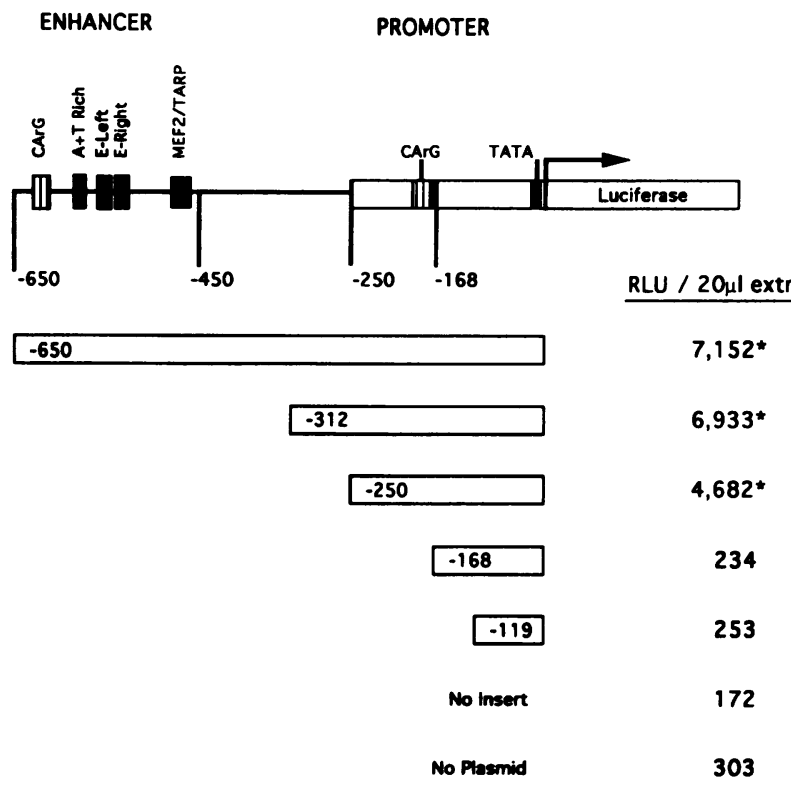

FIG. 3. Representative experiment demonstrating that the deletion of MCK enhancer sequences has no effect on expression in directly injected cardiac muscle. The data are from an experiment involving serial injections of the indicated constructs that were subcloned into pSVO-LUC (7). The conserved regulatory elements that are present in the enhancer include a CArG motif, an A/T-rich region that binds to the M-Hox homeodomain protein, E-box motifs that bind to helix-loop-helix factors, and an A/T-rich site that binds to the nuclear protein MEF2/TARP. In separate experiments, constructs were injected multiple times $(-650 \mathrm{MCK}, n=7 ;-312 \mathrm{MCK}$, $n=9 ;-250 \mathrm{MCK}, n=7$; $-168 \mathrm{MCK}, n=3 ;-119 \mathrm{MCK}, n=4$; pSVO-LUC, $n=4$ ), and the same expression pattern was obtained in the presence or absence of the coinjected control plasmid. In all cardiac injection experiments, the $-650 \mathrm{MCK},-312 \mathrm{MCK}$, and $-250 \mathrm{MCK}$ constructs consistently produced high levels of expression, while no significant luciferase activities were observed from the injection of $-168 \mathrm{MCK}$ and $-119 \mathrm{MCK}$ constructs relative to the promoterless control plasmid. *Expression was adjusted for transfection efficiency by normalization to CAT expression derived from $50 \mu \mathrm{g}$ of coinjected RSV-CAT. For all other figures, expression is displayed as total RLU, which represents the RLU that would be produced by the total volume of extract from an injected heart. This value is divided by the proportion of chloramphenicol acetylation when the CAT activity, produced by coinjection of the internal control plasmid, is assayed under standard conditions.

serial deletions were constructed between positions -250 and -168 of the MCK promoter to more precisely determine the sequences required for expression in cardiac muscle. This new series of constructs was made in plasmid pGL (Promega), which has a larger polylinker region. The -250 MCK promoter construct in the pGL vector was active in directly injected cardiac muscle (Fig. 5), but reproducibly lower levels of luciferase reporter activity were obtained relative to the pSVO-LUC-based construct used in previous experiments. Deletions to positions -221 and -190 did not diminish activity, but the promoter fragment from -168 to +54 was essentially inactive in cardiac muscle. The essential region deleted between positions -190 and -168 contains a sequence, CCATACAAGG, that is similar to the widely studied $\mathrm{CC}(\mathrm{A} / \mathrm{T})_{6} \mathrm{GG}$, or CArG motif, which forms the core of DNA regulatory elements in muscle-specific and immediate-early genes $(29,38)$. The sequence of this MCK promoter CArG motif is completely conserved between the rabbit, rat, mouse, and human genes $(16,18,37,45)$. 
A. SKELETAL MUSCLE

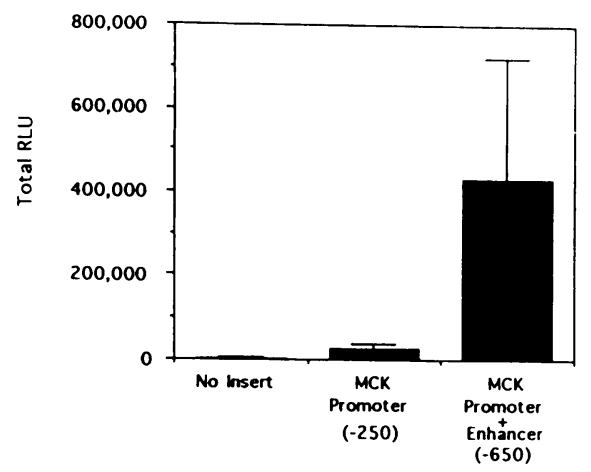

B. CARDIAC MUSCLE

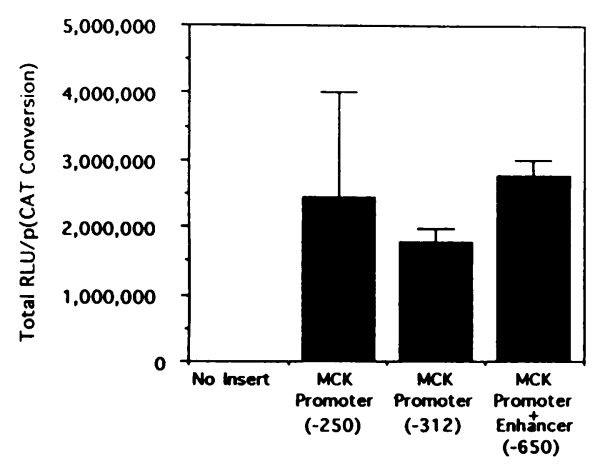

C. CARDIAC MUSCLE

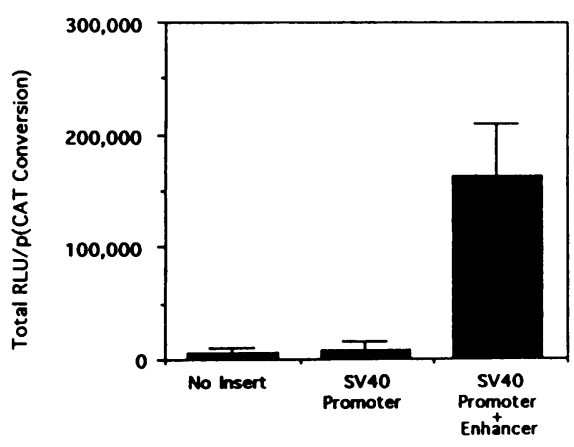

FIG. 4. MCK and SV40 enhancer activity in directly injected skeletal and cardiac muscle. (A) The MCK enhancer is essential for expression in skeletal muscle. Skeletal muscle was injected with 100 $\mu \mathrm{g}$ of plasmid DNA containing the rabbit MCK promoter and enhancer ( $-650 \mathrm{MCK})$ construct, the promoter alone ( $-250 \mathrm{MCK})$ construct, or a promoterless control plasmid (pSVO). Total RLU for these injected constructs was calculated from the following RLU values detected in $20-\mu$ l aliquots of the skeletal muscle extract prepared from separate injections: $-650 \mathrm{MCK}, 2,766,501,260$, $1,189,16,138$, and 1,$361 ;-250 \mathrm{MCK}, 333,287,233,688,185$, and 399; and pSVO, 266, 179, 172, and 153. RSV-CAT was also coinjected, but no CAT activity could be detected in these extracts, presumably because of the lower efficiency of DNA uptake by skeletal muscle. (B) The MCK enhancer has no effect on cardiac muscle expression. Cardiac muscle was injected with $100 \mu \mathrm{g}$ of $-650 \mathrm{MCK},-312 \mathrm{MCK},-250 \mathrm{MCK}$, and pSVO-LUC. (C) The SV40 enhancer is essential for expression in directly injected cardiac muscle. Cardiac muscle was injected with $100 \mu \mathrm{g}$ of plasmids pGL2-Control, pGL2-Promoter, and pGL2-Basic (Promega), which contain the SV40 promoter and enhancer, promoter alone, and no regulatory sequence upstream from luciferase gene, respectively. The data in each graph show the mean luciferase activity with the
Factor-binding properties of the CArG motif from the MCK promoter. The protein-binding properties of a probe to the CArG element of the rabbit MCK promoter were compared with those of the mouse c-fos SRE and the chicken skeletal actin MRE, which contain core $\mathrm{CC}(\mathrm{A} / \mathrm{T})_{6} \mathrm{GG}$ sequences and bind to the SRF and YY1 transcription factors in vitro (13, $38,40)$. Recombinant, $E$. coli-produced SRF and YY1 bound to all three CArG motif probes in an electrophoretic mobility shift assay (Fig. 6). Quantitative competition experiments with nonlabeled probes and equilibrium binding measurements indicated that SRF bound with similar affinities to all three sequences $\left(K_{d} \sim 4 \mathrm{nM}\right)$, but YY1 had a lower affinity for the CArG element of the MCK promoter $\left(K_{d}>25 \mathrm{nM}\right)$ than for the $\alpha$-actin MRE or the c-fos SRE (not shown; 13). The binding of SRF and YY1 transcription factors to this essential MCK promoter element suggests that the MCK, skeletal actin, and c-fos genes may be controlled by similar regulatory programs in adult cardiac muscle.

An adult cardiac tissue extract was fractionated and assayed for the presence of DNA-binding activities to the CArG element of the MCK promoter. Electrophoretic mobility shift assays with a ${ }^{32} \mathrm{P}$-labeled MCK-CArG probe revealed a number of nucleoprotein complexes, of which at least two predominant complexes appeared to be specific on the basis of their sensitivity to competition by a molar excess of nonlabeled MCK-CArG probe (Fig. 7). The specific complex with the slowest electrophoretic mobility, referred to as cI, was sensitive to competition by the c-fos SRE and the skeletal actin MRE but not to competition by MRE probes that are mutated at the $5^{\prime}$ and $3^{\prime}$ portions of the central CArG motif. This specificity for binding indicates that the cI nucleoprotein complex contains a protein that is similar or identical to SRF. The cII nucleoprotein complex was sensitive to competition by a molar excess of nonlabeled MRE and the MRE-CC mutant but not to the MRE-GG mutant. These data suggest that the protein in the cII complex binds asymmetrically to the CArG motif, and this binding specificity indicates that the cII nucleoprotein complex contains a protein that is similar or identical to YY1. Furthermore, the endogenous cardiac proteins that formed the $\mathrm{cI}$ and cII complexes had chromatographic properties and DNA-bound electrophoretic mobilities that were identical to those of SRF and YY1, respectively. The identification of specific SRF- and YY1-like activities in heart extracts suggests that these transcription factors may mediate the regulation of MCK gene expression in adult cardiac tissue.

\section{DISCUSSION}

Previous studies in skeletal muscle cell cultures have identified muscle-specific promoters and enhancers in the MCK genes from a number of species $(16,19,36,37,45)$. Most studies have focused on the cis-regulatory elements and transcription factors of the upstream enhancer. Key elements within this enhancer include the E-box motifs that bind to MyoD and other helix-loop-helix proteins $(22,30$, 42), an A/T-rich region that binds to a factor referred to as muscle enhancer factor 2 (MEF2) or the TA-rich recognition protein (TARP), which appears to be a member of the RSRF

standard error of the mean for four or more injections. To normalize injection efficiency, $50 \mu \mathrm{g}$ of pRSV-CAT was injected into each heart, and luciferase activity was adjusted to the levels of CAT expression. Total RLU represents the luciferase activity of the total extract volume. 

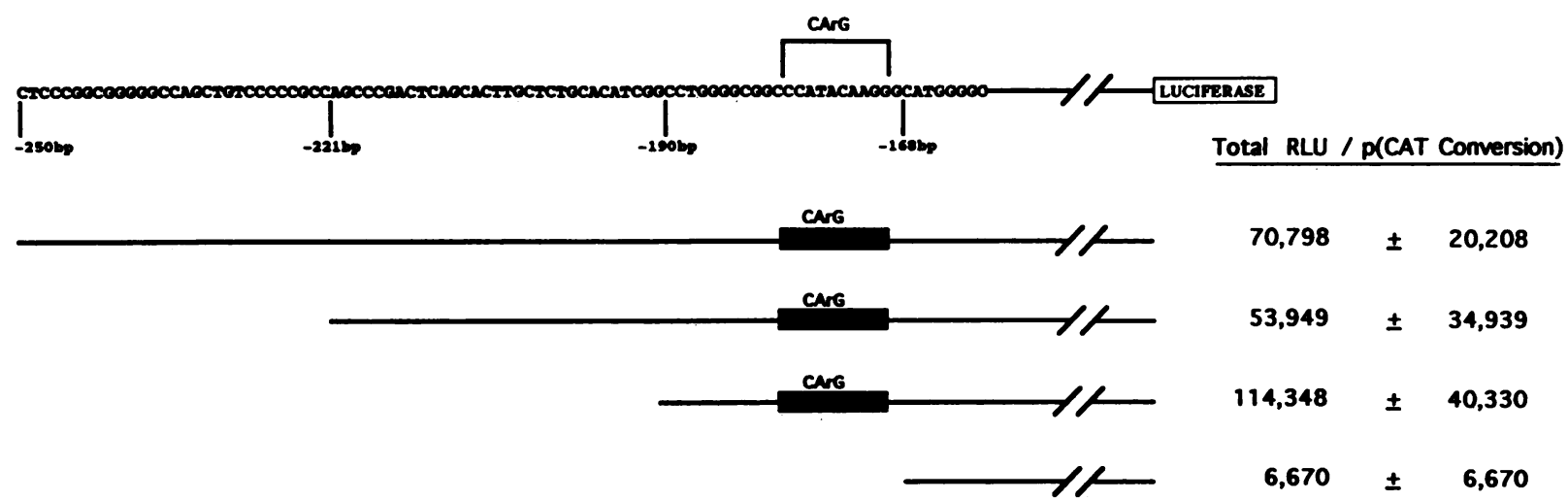

FIG. 5. Evidence that the CArG element of the MCK promoter is essential for expression in cardiac muscle. Activities of the rabbit MCK promoter constructs, subcloned into plasmid pGL2-Basic (Promega), were assessed in directly injected adult rat hearts. The constructs were from positions $-250,-221,-190$, and -168 , but all had the same $3^{\prime}$ end at position +54 relative to the start of transcription. The coding-strand sequence of the rabbit MCK promoter from positions -250 to -160 is shown, and the location of the CArG motif is indicated. For each construct, the average value for luciferase activity is provided with the standard error of mean for three or four serial injection experiments. Each injection was performed with $100 \mu \mathrm{g}$ of test plasmid and $50 \mu \mathrm{g}$ of RSV-CAT to normalize transfection efficiency. Total RLU represents the luciferase activity of the total extract volume.

(related to SRF) family of proteins $(12,17,34)$, and a second $\mathrm{A} / \mathrm{T}$-rich region that binds to a homeodomain protein referred to as M-Hox (6). Much less attention has been focused on the promoter because its expression is greatly attenuated by the removal of the enhancer sequences in most cell culture systems. The direct plasmid injection technique was used in this study to evaluate the relative contributions of MCK gene regulatory sequences toward expression in adult cardiac and skeletal muscle. In adult skeletal muscle, the enhancer was required for significant levels of expression. However, in cardiac muscle this sequence was completely dispensable. Instead, a 22-bp promoter fragment that con-

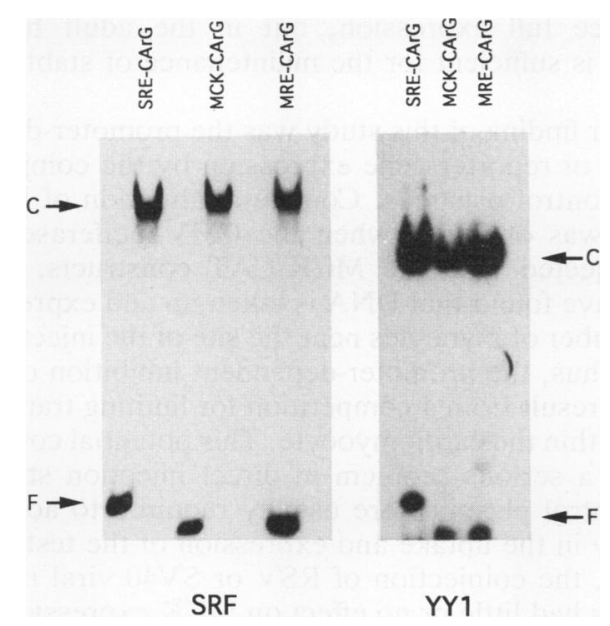

FIG. 6. Binding of transcription factors YY1 and SRF to the CArG element of the rabbit MCK promoter. Radiolabeled probes of the rabbit MCK promoter CArG (MCK-CArG), the mouse c-fos promoter SRE (SRE-CArG), and the chicken skeletal actin promoter MRE (MRE-CArG) were analyzed in an electrophoretic mobility shift assay for binding to recombinant, $E$. coli-produced SRF and YY1. F, free (unbound) probe; C, probe-factor complexes. Binding reaction mixtures contained $1 \mathrm{nM}^{32} \mathrm{P}$-labeled DNA probe, $0.2 \mu \mathrm{g}$ of poly(dI-dC) $)_{2}$, and $0.02 \mathrm{pmol}$ of YY1 or $0.03 \mathrm{pmol}$ of SRF. Positions of the free DNA (F) and the nucleoprotein complexes (C) are indicated. tains a CArG sequence motif was found to be essential for expression in adult heart. These data demonstrate that MCK expression is controlled by different regulatory programs in adult cardiac and skeletal muscle tissues.

These data are intriguing in light of the skeletal musclespecific expression pattern of the helix-loop-helix proteins that activate myogenesis and bind to E-box regulatory elements $(30,42)$. These proteins, MyoD, myogenin, MRF4, and myf-5, are not expressed in cardiac muscle or any other cell type, and much effort has been expended to isolate the

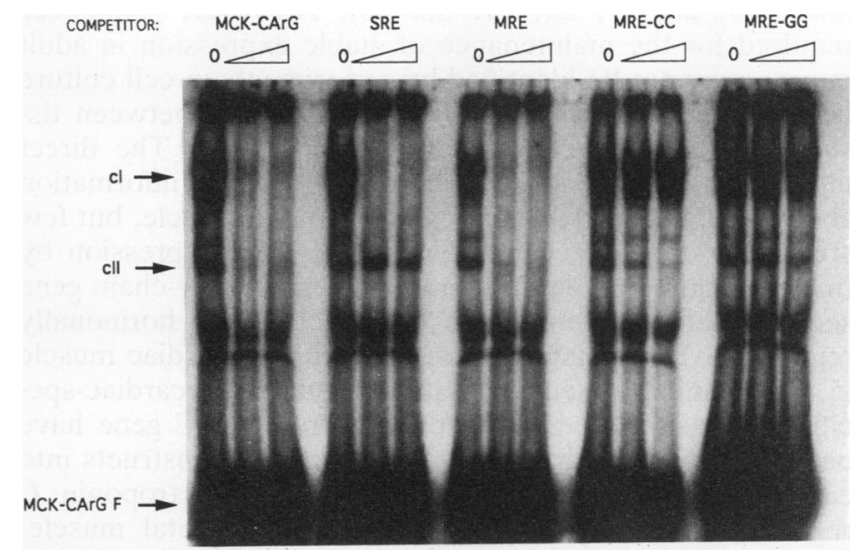

FIG. 7. Evidence that the CArG element of the MCK promoter binds SRF- and YY1-like activities in cardiac extracts. Approximately $8 \mu \mathrm{g}$ of protein from a heparin-Sepharose column fraction of adult rat cardiac tissue extract was incubated with $1 \mathrm{nM}^{32} \mathrm{P}$-labeled probe of the rabbit MCK promoter CArG motif (MCK-CArG) and $0.4 \mu \mathrm{g}$ of poly(dI-dC $)_{2}$. Each set of reactions contained none (0), 30 $\mathrm{ng}$ (second lane), or $100 \mathrm{ng}$ (third lane) of the indicated competitor. Competitors were oligonucleotide duplexes of the rabbit MCK promoter CArG element (MCK-CArG), the mouse c-fos SRE, and the chicken skeletal actin MRE. The actin MRE-CC and MRE-GG mutants have substitutions at the upstream and downstream portions of the $\mathrm{CC}(\mathrm{A} / \mathrm{T})_{6} \mathrm{GG}$ motif, respectively (13). Complexes cI and cII refer to SRF- and YY1-like activities, respectively, that bound to the MCK-CArG probe. MCK-CArG F refers to the free (unbound) probe. 
cardiac homologs of these proteins. Part of the rationale for searching for cardiac-specific helix-loop-helix proteins derives from the assumption that the same promoter regulatory sequences, including the $\mathrm{E}$ box, are required for expression in cardiac muscle as well as skeletal muscle. However, the data from this study suggest that different MCK regulatory sequences are required for expression in fully differentiated skeletal and cardiac muscle, thereby implicating different transcription factors in this control. Of course, these data do not exclude the possibility of cardiac-specific helix-loophelix proteins that regulate other genes or activate MCK expression at earlier stages of cardiomyocyte development.

The data presented here show that a CArG motif in the promoter is critical for MCK expression in adult cardiac tissue. This CArG sequence is completely conserved between the rabbit, mouse, rat, and human MCK genes $(16,18$, $37,45)$, but the functional significance of this MCK sequence had not been documented prior to this study. The CArG motif forms the core of regulatory elements in a number of muscle-specific as well as immediate-early genes $(29,38)$, and the proximal CArG motif of the skeletal actin gene is essential for basal expression and can confer tissue-specific regulation to heterologous promoter constructs $(35,40,41)$. The nuclear proteins SRF and YY1 bind to many CArG elements in vitro and function as positive and negative transcription factors, respectively (13). Recombinant SRF and YY1 also bind to the CArG element from the MCK promoter. These data suggest that the MCK gene responds to the same regulatory signals in adult cardiac muscle as do the muscle actin and c-fos genes. The identification of SRF-like and YY1-like DNA-binding activities in extracts from adult cardiac muscle further supports this hypothesis.

Cardiac-specific expression has been primarily analyzed by transfection studies in primary cultures of embryonic cardiomyocytes, and in some cases this regulation has been deduced from transfection studies in skeletal muscle cell lines $(15,26,27,29,31,32,46)$. However, sequences required for the maintenance of stable expression in adult muscle may not be identified by experiments in cell culture because patterns of isoform expression differ between tissues and cultured cells $(3,8,9,14,28,39)$. The direct injection method has the potential to provide information about regulation in terminally differentiated muscle, but few studies have analyzed muscle-specific gene expression by this procedure. To date, the rat $\alpha$-myosin heavy-chain gene sequences have been shown to be active and hormonally regulated when constructs are injected into cardiac muscle $(5,21)$. Similarly, sequences that regulate the cardiac-specific expression of the slow/cardiac troponin $\mathrm{C}$ gene have been identified by directly injecting plasmid constructs into cardiac muscle (33). These cardiac-specific, troponin C regulatory regions are distinct from the skeletal musclespecific enhancer that is required for expression in the murine $\mathrm{C} 2 \mathrm{C} 12$ cell lines. Recently, transgenic mice studies have revealed that the myosin light-chain-2 gene is also regulated by different sequences in cardiac and skeletal muscle (23). Thus, the myosin light-chain-2, troponin $\mathrm{C}$, and MCK genes all appear to respond to different regulatory programs in adult cardiac and skeletal muscle.

A previous study of mouse MCK expression in transgenic mice found that the 5 ' enhancer and unidentified upstream elements were required for expression in heart and that the promoter sequences alone were unable to activate reporter gene expression in skeletal or cardiac muscle (20). These data are in marked contrast to the findings of this study, in which the rabbit MCK promoter sequences were sufficient for expression in directly injected cardiac muscle. There are a number of possible explanations for this apparent discrepancy. One possibility is that the rabbit MCK constructs examined here lack key cardiac-specific regulatory elements, and the observed pattern of expression does not accurately reflect that of the entire gene. We cannot completely rule this possibility out, but similar levels of reporter gene expression were produced by the MCK promoter and viral (SV40 and RSV) regulatory sequences, suggesting that the MCK constructs contain relatively active DNA regulatory sequences. In comparison, cardiac-specific expression from the rat $\alpha$-myosin heavy-chain gene was 20 -fold less active than expression from RSV regulatory sequences in directly injected heart (5). Furthermore, the inclusion of an additional $550 \mathrm{bp}$ of upstream MCK gene sequences had no detectable effect on expression in cardiac tissue (not shown). An alternative possibility is that different patterns of expression are caused by differences in the state of the test DNA within the cell. Previous studies have shown that the circular DNA molecules delivered to myocytes by injection remain extrachromosomal (43), whereas tandem arrays of linearized molecules occur in the genomes of transgenic mice. We note, however, that the data obtained by direct gene injection and by transgenic mice studies are in agreement with data for skeletal muscle, and it is probably unlikely that these technical differences alone are the basis for the discrepancy in the cardiac-specific expression. Another possibility is that the transgenic and direct injection procedures provide information about regulatory events that occur at different stages of development. Presumably, direct injection provides information only about the sequences that are required for the maintenance of stable expression in terminally differentiated tissue. However, the ultimate expression of a transgene in the adult may require additional elements that respond to early developmental signals or prevent the permanent inactivation of the gene in the embryo. Thus, it is possible that the enhancer and upstream sequences of MCK are required at early stages of cardiomyocyte development to produce full expression, but in the adult heart, the promoter is sufficient for the maintenance of stable expression.

Another finding of this study was the promoter-dependent inhibition of reporter gene expression by the coinjection of internal control plasmids. Complete inhibition of MCK expression was observed when the CMV-luciferase plasmid was coinjected with the MCK-CAT constructs. Previous studies have found that DNA is taken up and expressed in a small number of myocytes near the site of the injection $(1,5$, 43 ), and thus, the promoter-dependent inhibition of expression may result from a competition for limiting transcription factors within the cardiomyocyte. This potential competition can pose a serious problem in direct injection studies because control plasmids are usually required to account for variability in the uptake and expression of the test plasmid. However, the coinjection of RSV or SV40 viral regulatory sequences had little or no effect on MCK expression. These data demonstrate that the problem of promoter-dependent competition between the coinjected plasmids can be circumvented, at least in part, by the proper choice of the internal control plasmid.

In summary, the direct injection of rabbit MCK gene constructs has revealed that the promoter is sufficient for expression in cardiac muscle and that the upstream enhancer is required only for full activity in skeletal muscle. Further analysis of the MCK promoter revealed a conserved CArG motif that was essential for expression in directly injected 
cardiac muscle. This CArG motif bound to recombinant SRF and YY1 transcription factors in vitro, and adult cardiac extracts contained SRF- and YY1-like binding activities. These observations provide evidence for different mechanisms of MCK gene regulation in adult cardiac and skeletal muscle tissues. This study also demonstrates the utility of the direct gene injection method for mapping cardiac- and skeletal muscle-specific regulatory elements within promoters and enhancers.

\section{ACKNOWLEDGMENTS}

This work was supported by grants from the NIH (Public Health Service grants AR40197 and HL45345) and a grant from the Mather Foundation to K.W. K.W. is an established investigator of the American Heart Association. C.V.P. is supported by NEO affiliate of the American Heart Association fellowship F286. A.G. is a postdoctoral fellow of the Ministerio de Educación y Ciencia, Spain. C.K.V. was supported by National Institutes of Health Training grant HL-07653.

We thank M. Z. Gilman for the bacterial SRF expression plasmid, R. Patrick for technical assistance, and D. Sucui for experiments that first demonstrated skeletal muscle gene expression in our laboratory.

\section{REFERENCES}

1. Acsadi, G., G. Dickson, D. R. Love, A. Jani, F. S. Walsh, A. Gurusinghe, J. A. Wolff, and K. E. Davies. 1991. Human dystrophin expression in $\mathrm{mdx}$ mice after intramuscular injection of DNA constructs. Nature (London) 352:815-818.

2. Acsadi, G., S. S. Jiao, A. Jani, D. Duke, P. Williams, W. Chong, and J. A. Wolff. 1991. Direct gene transfer and expression into rat heart in vivo. New Biol. 3:71-81.

3. Bains, W., P. Ponte, H. Blau, and L. Kedes. 1984. Cardiac actin is the major actin gene product in skeletal muscle cell differentiation in vitro. Mol. Cell. Biol. 4:1449-1453.

4. Brasier, A. R., J. E. Tate, and J. F. Habener. 1989. Optimized use of the firefly luciferase assay as a reporter gene in mammalian cell lines. BioTechniques 7:1116-1120.

5. Buttrick, P. M., A. Kass, R. N. Kitsis, M. L. Kaplan, and L. A. Leinwand. 1992. Behavior of genes directly injected into the rat heart in vivo. Circ. Res. 70:193-198.

6. Cserjesi, P., B. Lilly, L. Bryson, Y. Wang, D. Sassoon, and E. N. Olson. 1992. MHox: a mesodermally-restricted homeodomain protein that binds an essential site in the muscle creatine kinase enhancer. Development 15:1087-1101.

7. DeWet, J. R., K. V. Wood, M. DeLuca, D. R. Helinski, and S. Subramani. 1987. Firefly luciferase gene: structure and expression in mammalian cells. Mol. Cell. Biol. 7:725-737.

8. Eppenberger, M. E., I. Hauser, T. Baechi, M. C. Schaub, U. T. Brunner, C. A. Dechesne, and H. M. Eppenberger. 1988. Immunocytochemical analysis of the regeneration of myofibrils in long-term cultures of adult cardiomyocytes of the rat. Dev. Biol. 130:1-15.

9. Eppenberger-Eberhardt, M., I. Hauser, T. Baeci, M. C. Schaub, U. T. Brunner, C. A. Dechesne, and H. M. Eppenberger. 1990. Reexpression of alpha-smooth muscle actin isoform in cultured adult rat cardiomyocytes. Dev. Biol. 139:269-278.

10. Gorman, C. M., G. T. Merlino, M. C. Willingham, I. Pastan, and B. H. Howard. 1982. The Rous sarcoma virus long terminal repeat is a strong promoter when introduced into a variety of eukaryotic cells by DNA mediated transfection. Proc. Natl. Acad. Sci. USA 79:6777-6781.

11. Gorman, C. M., L. F. Moffat, and B. H. Howard. 1982. Recombinant genomes which express chloramphenicol acetyltransferase in mammalian cells. Mol. Cell. Biol. 2:1044-1051.

12. Gossett, L. A., D. J. Kelvin, E. A. Sternberg, and E. N. Olson. 1989. A new myocyte-specific enhancer-binding factor that recognizes a conserved element associated with multiple muscle-specific genes. Mol. Cell. Biol. 9:5022-5033.

13. Gualberto, A., D. LePage, G. Pons, S. L. Mader, K. Park, M. L. Atchinson, and K. Walsh. 1992. Functional antagonism between
YY1 and the serum response factor. Mol. Cell. Biol. 12:4209_ 4214.

14. Gunning, P., P. Ponte, H. Blau, and L. Kedes. 1983. Alphaskeletal and alpha-cardiac actin genes are coexpressed in adult human skeletal muscle and heart. Mol. Cell. Biol. 3:1985-1995.

15. Henderson, S. A., M. Spencer, A. Sen, C. Kumar, M. A. Siddiqui, and K. R. Chien. 1989. Structure, organization, and expression of the rat cardiac myosin light chain-2 gene. Identification of a 250-base pair fragment which confers cardiacspecific expression. J. Biol. Chem. 264:18142-18148.

16. Horlick, R. A., and P. A. Benfield. 1989. The upstream musclespecific enhancer of the rat muscle creatine kinase gene is composed of multiple elements. Mol. Cell. Biol. 9:2396-2413.

17. Horlick, R. A., G. M. Hobson, J. H. Patterson, M. T. Mitchell, and P. A. Benfield. 1990. Brain and muscle creatine kinase genes contain common TA-rich recognition protein-binding regulatory elements. Mol. Cell. Biol. 10:4826-4836.

18. Jaynes, J. B., J. S. Chamberlain, J. N. Buskin, J. E. Johnson, and S. D. Hauschka. 1986. Transcriptional regulation of the muscle creatine kinase gene and regulated expression in transfected mouse myoblasts. Mol. Cell. Biol. 6:2855-2864.

19. Jaynes, J. B., J. E. Johnson, J. N. Buskin, C. L. Gartside, and S. D. Hauschka. 1988. The muscle creatine kinase gene is regulated by multiple upstream elements, including a musclespecific enhancer. Mol. Cell. Biol. 8:62-70.

20. Johnson, J. E., B. J. Wold, and S. D. Hauschka. 1989. Muscle creatine kinase sequence elements regulating skeletal and cardiac muscle expression in transgenic mice. Mol. Cell. Biol. 9:3393-3399.

21. Kitsis, R. N., P. M. Buttrick, E. M. McNally, M. L. Kaplan, and L. A. Leinwand. 1991. Hormonal modulation of a gene injected into rat heart in vivo. Proc. Natl. Acad. Sci. USA 88:4138-4142.

22. Lassar, A. B., J. N. Buskin, D. Lockshon, R. L. Davis, S. Apone, S. D. Hauschka, and H. Weintraub. 1989. MyoD is a sequencespecific DNA binding protein requiring a region of myc homology to bind to the muscle creatine kinase enhancer. Cell 58:823-831.

23. Lee, K. J., R. S. Ross, H. A. Rockman, A. N. Harris, T. X. O'Brien, M. van Bilsen, H. E. Shubeita, R. Kandolf, G. Brem, J. Price, S. M. Evans, H. Zhu, W. M. Franz, and K. R. Chien. 1992. Myosin light chain-2 luciferase transgenic mice reveal distinct regulatory programs for cardiac and skeletal musclespecific expression of a single contractile protein gene. J. Biol. Chem. 267:15875-15885.

24. Lim, C. S., G. D. Chapman, R. S. Gammon, J. B. Muhlestein, R. P. Bauman, R. S. Stack, and J. L. Swain. 1991. Direct in vivo gene transfer into the coronary and peripheral vasculatures of the intact dog. Circulation 83:2007-2011.

25. Lin, H., M. S. Parmacek, G. Morle, S. Bolling, and J. M. Leiden. 1990. Expression of recombinant genes in myocardium in vivo after direct injection of DNA. Circulation 82:2217-2221.

26. Long, C. S., C. P. Ordahl, and P. C. Simpson. 1989. Alpha 1-adrenergic receptor stimulation of sarcomeric actin isogene transcription in hypertrophy of cultured rat heart muscle cells. J. Clin. Invest. 83:1078-1082.

27. Mar, J. H., P. B. Antin, T. A. Cooper, and C. P. Ordahl. 1988. Analysis of the upstream regions governing expression of the chicken cardiac troponin $T$ gene in embryonic cardiac and skeletal muscle cells. J. Cell Biol. 107:573-585.

28. Mayer, Y., H. Czosnek, P. E. Zeelon, D. Yafie, and U. Nudel. 1984. Expression of the genes coding for the skeletel muscle and cardiac actins in the heart. Nucleic Acids Res. 12:1087-1100.

29. Minty, A., and L. Kedes. 1986. Upstream regions of the human cardiac actin gene that modulate its transcription in muscle cells: presence of an evolutionarily conserved repeated motif. Mol. Cell. Biol. 6:2125-2136.

30. Olson, E. N. 1990. MyoD family: a paradigm for development? Genes Dev. 4:1454-1461.

31. Parker, T. G., K. L. Chow, R. J. Schwartz, and M. D. Schneider. 1992. Positive and negative control of the skeletal alpha-actin promoter in cardiac muscle. A proximal serum response element is sufficient for induction by basic fibroblast growth factor (FGF) but not for inhibition by acidic FGF. J. Biol. Chem. 
267:3343-3350.

32. Parmacek, M. S., and J. M. Leiden. 1989. Structure and expression of the murine slow/cardiac troponin $\mathrm{C}$ gene. J. Biol. Chem. 264:13217-13225.

33. Parmacek, M. S., A. J. Vora, T. Shen, E. Barr, F. Jung, and J. M. Leiden. 1992. Identification and characterization of a cardiac-specific transcriptional regulatory element in the slow/ cardiac troponin C gene. Mol. Cell. Biol. 12:1967-1976.

34. Pollock, R., and R. Treisman. 1991. Human SRF-related proteins: DNA-binding properties and potential regulatory targets. Genes Dev. 5:2327-2341.

35. Santoro, I. M., and K. Walsh. 1991. Natural and synthetic DNA elements with the CArG motif differ in expression and proteinbinding properties. Mol. Cell. Biol. 11:6296-6305.

36. Sternberg, E. A., G. Spizz, W. M. Perry, D. Vizard, T. Weil, and E. N. Olson. 1988. Identification of upstream and intragenic regulatory elements that confer cell-type-restricted and differentiation-specific expression on the muscle creatine kinase gene. Mol. Cell. Biol. 8:2896-2909.

37. Trask, R. V., A. W. Strauss, and J. J. Billadello. 1988. Developmental regulation and tissue-specific expression of the human muscle creatine kinase gene. J. Biol. Chem. 263:17142-17149.

38. Treisman, R. 1990. The SRE: a growth factor responsive transcriptional regulator. Semin. Cancer Biol. 1:47-58.

39. Vandekerckhove, J., G. Bugiasky, and M. Buckingham. 1982. Simultaneous expression of skeletal muscle and heart actin protein in various striated muscle tissues and cells. J. Biol. Chem. 261:1838-1843.

40. Walsh, K. 1989. Cross-binding of factors to functionally different promoter elements in c-fos and skeletal actin genes. Mol. Cell. Biol. 9:2191-2201.

41. Walsh, K., and P. Schimmel. 1988. DNA-binding site for two skeletal actin promoter factors is important for expression in muscle cells. Mol. Cell. Biol. 8:1800-1802.

42. Weintraub, H., V. J. Dwarki, I. Verma, R. Davis, S. Hollenberg, L. Snider, A. Lassar, and S. J. Tapscott. 1991. Muscle-specific transcriptional activation by MyoD. Genes Dev. 5:1377-1386.

43. Wolfi, J. A., R. W. Malone, P. Williams, W. Chong, G. Acsadi, A. Jani, and P. L. Felgner. 1990. Direct gene transfer into mouse muscle in vivo. Science 247:1465-1468.

44. Wolff, J. A., P. Williams, G. Acsadi, S. Jiao, A. Jani, and W. Chong. 1991. Conditions affecting direct gene transfer into rodent muscle in vivo. BioTechniques 11:474-485.

45. Yi, T. M., K. Walsh, and P. Schimmel. 1991. Rabbit muscle creatine kinase: genomic cloning, sequencing, and analysis of upstream sequences important for expression in myocytes. Nucleic Acids Res. 19:3027-3033.

46. Zhu, H., A. V. Garcia, R. S. Ross, S. M. Evans, and K. R. Chien. 1991. A conserved 28-base-pair element (HF-1) in the rat cardiac myosin light-chain-2 gene confers cardiac-specific and alpha-adrenergic-inducible expression in cultured neonatal rat myocardial cells. Mol. Cell. Biol. 11:2273-2281. 